\title{
The Impact of Big Data Analytics Capabilities on Competitive Advantage Applied on "Etisalat Egypt"
}

\author{
Amira M. Omar \\ Faculty of Economics and International Trade \\ Egyptian Chinese University, Cairo \\ Arab Republic of Egypt \\ aomar@ecu.edu.eg
}

\begin{abstract}
The purpose of this study is to investigate how Big Data Analytics is used and perceived to affect a firm's competitive advantage. The study will focus on the telecommunication sector, due to the high volume of data being used for analysis in this sector; it is always an area of great interest. This paper investigates the role that Big Data Analytics Capabilities play in achieving a competitive advantage in the Egyptian telecommunication sector. Using the Dynamic Capabilities framework, this paper looks at how a firm can gain an advantage from big data.

For collecting data, the study adopted the questionnaire method; the study used the questionnaire-based survey method; the study used two questionnaires; one for big data analysis department employees to investigate the independent variable Big Data Analytics capabilities, and the other one for the top and middle managerial levels employees to investigate the dependent variable competitive advantage.

The results show that there is a statistically significant impact of "Big Data Analytics Capabilities" on Competitive advantage. Infrastructure flexibility and management capabilities were relatively more important than Personnel Expertise between all the dimensions of Big Data Analytics capabilities. But these differences are small, so all the dimensions should be given the same value in building Big Data Analytics capabilities. Management in the telecommunication sector should take into account that enhancing Big Data capabilities and considering big data as part of their operations can improve their Competitive Advantage and their Performance.
\end{abstract}

Keywords: Big Data Analytics, Big Data Analytics Capability, Competitive Advantage

\section{Introduction}

Big Data has achieved a better position every year since the $21^{\text {st }}$ century. (Alguliyev \& Hajirahimova, 2014) It's considered among the topics that attract many researchers since a new development Technology makes it possible to analyze all the incremental and easily available data. However, enormous data is a major opportunity but at the same time it's a challenge; as it's not about how to process it, but rather on how it can be used to make the right decisions through transforming it into meaningful knowledge. (Charles \& Gherman, 2013)

The size of Big Data is the most important factor that differentiates big data from traditional data, but "big" is not just a matter of size; it might contain volume, velocity, or variety (Gobble, 2013).

Big data is understood to mean enormous information that traditional database tools unable to manage. The adequate storage capacity and computing power for processing of this data are essential. It is recognized that supercomputers can carry out a lot of arithmetic operations per second. Big Data Analytics technology can

\footnotetext{
* This article was submitted in September 2018, accepted for publishing in November 2018 and published on December 2020.

(C) Arab Administrative Development Organization- League of Arab States, 2020, pp 337-356، DOI: 10.21608/aja.2020.131098
} 
attain revolutionary changes in business management, in fields such as commerce, industry, agriculture health, tourism, and so on. (Fosso et al., 2015)

Information technology (IT) investments form an important portion of capital expenditure of firms (Ravichandran \& Liu, 2011), and organizations continue to invest in IT in expectation of benefits like improved profitability, productivity, and market share (Brien, Marakas \& Behl, 2010). Strategy researchers differ on the question of whether IT can provide sustained competitive advantage (Dewan \& Ren, 2011), although there is a general agreement among them that IT improves productivity (Brynjolfsson \& Hitt, 2000). Some researchers suggest that IT used to provide a competitive advantage in previous days when it was costly and not obtainable to all organizations in the industry, however, decreasing costs of computing, and availability of software packages, has made IT everywhere (Chae; Koh \& Prybutok, 2014).

A competitive advantage is built on a set of strategically relevant resources. The resource-based perspective takes the business's internal approach. The business's unrivaled capabilities in terms of knowledge and managerial ability are significant resources that might create sustained competitive advantages (Omerzel; Gulev, 2011).

Therefore, this study aims to investigate the effect of big data analytics on competitive advantages in the telecommunication industry.

To address the research objectives, this paper is structured as follows: First, the presentation of a literature review on big data analytics capabilities and competitive advantages. This is followed by determining the problem statement, objectives, variables' model and research hypothesis are presented, and then followed by designing the research method. The subsequent sections present the data analysis and findings of the study. At last, the research clarified the conclusion and the recommendations.

\section{Literature Review}

\section{Big Data Analytics Capabilities Concepts}

Big data analytics (BDA) is rising as a hot topic among scholars and practitioners, Gartner (2012) defines it as "Big data is high-volume, high-velocity and/or high-variety information assets that demand cost-effective, innovative forms of information processing that enable enhanced insight, decision making, and process automation". (Gartner IT Glossary, 2012). In this definition, Gartner's concern is about the benefits that organizations could achieve from Big Data analytics. "Big data shall mean the datasets that could not be perceived, acquired, managed and processed by traditional IT and software/hardware tools within a tolerable time" (Chen; Mao \& Liu, 2014) this definition relating to the tools and time that big data needed to be managed.

Julio Hernandez (Hernandez, 2013) research with CPG executives revealed that firms continue to struggle with essential issues related to Analytics data, methods, organization, and technology. Analytics capabilities are deployed frequently to generate hindsight_- "rearview" descriptions of what happened_rather than forward-looking insights that can be used to make operational, managerial, and strategic decisions.

Big data considered as a holistic approach to managing, processing and analyzing the $5 \mathrm{~V}$ data-related dimensions (i.e., volume, variety, velocity, veracity, and value) to create actionable ideas for delivering sustained value, measuring performance and establishing competitive advantages, and it has been defined for this reason as "Big data is where the data volume, acquisition velocity, or data representation [variety] limits the ability to perform effective analysis using traditional relational approaches or requires the use of significant horizontal scaling for efficient processing"(Cooper \& Mell, 2012). Volume is the quantity of data produced by humans and machines. Variety is the number of types of data. To be more detailed, the variety of Data 
includes both structured and unstructured data. Unstructured data lack a predefined structure and normally stems from social networks, web pages, and other similar communication channels. And finally, velocity is the speed of data processing. As indicated by the $3 \mathrm{Vs}$ model, the challenges of big data management stem from the expansion of all three properties, rather than just the volume alone (Preimesberger, 2011).

Big data analytics capabilities consist of three main dimensions, that is, management, infrastructure, and personnel capabilities. For instance, McAfee and Brynjolfsson (McAfee \& Brynjolfsson, 2012) propose personnel management, technology infrastructure, and corporate decision-making as vital capabilities across organizations. likewise, Kiron, Prentice, \& Ferguson identified organization culture, employees' analytics skills and analytics platform as main dimensions of BDA. (Likewise, Kiron, Prentice \& Ferguson, 2014) Besides, Davenport highlights that management, people, and technology dimensions are interlinked in the big data environment, and that help to enhance organization performance. (Davenport; Barth \& Bean, 2012) Also, Barton and Court (2012) specify that management capability is important to optimize decision models; technology capability is essential to explore and manage a variety of data; and finally, data science capability is important to understand, build up and activate analytics models. (Barton \& Court, 2012)

Vincent Charles's research presents a perspective that combines the conventional and more technical dimensions of big data with the more challenging dimensions of context, connectedness, and complexity. It is argued that by understanding this expanded perspective, decision-makers can much better appreciate the value-added which big data has to offer and how it can become a competitive advantage for the firm. (Charles \& Gherman, 2013)

Constantiou research revealed that the usefulness of big data rests on their steady updatability, a condition that reduces the time within which this data is useful or relevant. Jointly, these attributes challenge established rules of strategy making as these are manifested in the canons of procuring structured information of lasting value that addresses specific and long-term organizational objectives. The developments underlying big data, thus, seem to carry important implications for strategy making, and the data and information practices with which strategy has been associated (Constantiou \& Kallinikos, 2015).

Kiron \& Shockley Organizations that have moved beyond baseline analytics are using analytics to focus on the future, on the customer, and on increasing efficiencies at superior depth and scope. Transformed companies tend to have a data-oriented culture as well as competency in two areas: information management and analytic expertise. Both competencies require capabilities and resources beyond what is typically invested in baseline analytics (Kiron \& Shockley, 2011).

Samuel Fosso's research proposes a big data analytics capability (BDAC) model. The study examins the direct effects of BDAC on firm performance, as well as the mediating effects of process-oriented dynamic capabilities (PODC) on the relationship between BDAC and firm performance. The study collects data from 297 Chinese IT managers and business analysts with big data and business analytic experience. The findings confirm the value of the entanglement conceptualization of the hierarchical BDAC model. The results also confirm the strong mediating role of PODC in improving insights and enhancing firm performance. (Fosso et al., 2016)

Hajirahimova research is devoted to the study of big data strategies. Big data policy of such countries as the USA, Australia, China, Korea, and others has been interpreted in the research. The study confirms that the in-depth analysis of large volumes of data can play a crucial role in making the best decision. It is important to use this technology by the government for serving the citizens, solution of national problems (healthcare; terrorism; job creation; natural disasters, etc.) and to identify dangers in advance. Big data has great potential to help healthcare and social security issues as the prevention of infectious diseases, terrorism, disaster, and global risks. (Hajirahimova et al., 2016) 
Christian Dremel's research conducted 16 interviews with experts from an IT-strategy consulting firm. The resulting capability model consists of eight capability groups that contain 34 capabilities. It provides a basis to systematically develop the necessary capabilities for the adoption and strategic usage of big data analytics. In sum, the research identified 34 generic capabilities that have been assigned to eight capability fields: Customer Relationship Management, Partner Life Cycle Management, Product/Service Life Cycle Management, Enterprise Risk Management, Strategy Development, Transformation Competence, Enterprise Architecture, and Process Management, and Information Management. The capability model gives an initial, yet unique and empirically grounded overview of the competencies that are generally required for BDA (Dremel et al., 2017).

\section{Competitive Advantage:}

Now BDA can improve business efficiency and effectiveness because of its high operational and strategic potential. There is a positive relationship between the use of customer analytics and organization performance as identified in the emerging literature on BDA (Germann; Lilien; Fiedler \& Kraus, 2014). BDA progressively becomes a vital component of decision-making processes in businesses (Hagel, 2015); as BDA allows companies to analyze and manage strategy through a data lens (BRANDS, 2014). BDA is now considered as "a major differentiator between high performing and low-performing organizations"; as it helps firms become more proactive and futuristic, decreases customer acquisition costs by about $47 \%$, and increase firm revenue by about $8 \%$ (LIU, 2014). Target Corporation as an example uses BDA through its loyalty card program to follow customers' purchasing behaviors and expect their future buying trends.

Another example of a firm that is capitalizing on BDA is Amazon.com. Almost 35\% of purchases made on Amazon.com are generated from customized purchase recommendations to customers derived from BDA (WILLS, 2014). Another example GE, as it's planning to use BDA to improve the efficiency of the 1,500 gas turbines it monitors employing software and network optimization, as well as to improve the dispatching of service and the coordination of gas and power systems. If achieved, benefits could initiate $\$ 66$ billion in fuel savings over the next 15 years (Ward, 2014).

BDA is expected to have incredible impacts on different industries. For example, major retailing firms are presently leveraging big data capabilities to improve customer experience, reduce deception, and make justin-time recommendations (Tweney, 2013). Besides, BDA is considered to be an enabler of asset and business process monitoring in manufacturing and operations management (Davenport; Barth \& Bean, 2012b)

\section{Research Problem}

Now it's essential to know how companies adopt technologies rather than the kind of technologies they are adopted because IT has considered a commodity in recent years. Thus, this approach focuses on BDA capabilities and how companies can use BDA to achieve competitiveness (Carr, 2003).

Furthermore, there has been a long debate on what the impact of IT on an organization's competitiveness is, but no clear answer was agreed upon. Although there is recognition of the importance of information systems for organizations, academic studies have not agreed on the role of information systems as a driver of organizations' competitiveness (Wade \& Nevo, 2011).

The purpose of this study is to investigate how BDA is used and perceived to affect a firm's competitive advantage. The study will focus on the telecommunication sector, due to the high volume of data being used for analysis in this sector; it is always an area of great interest. This paper investigates the role that big data analytics capabilities play in achieving a competitive advantage in the Egyptian telecommunication sector. Using the Dynamic Capabilities framework, this paper looks at how a firm can gain an advantage 
from big data. Furthermore, this paper provides an example of how to build a capability in Digital Data Generation that can help a firm gain an advantage over its competitors in the Egyptian telecommunication sector. The previous discussion leads to the main question of the present research which is the following:

"What is the impact of Big Data Analytics capabilities on competitive advantage in the telecommunication industry?"

\section{Research Objectives}

This paper aims to identify BDA capabilities and its impact on the telecommunication firms' competitive advantages and Help managers in the telecommunication sector to be more aware of the theoretical and practical understanding of how BDA can affect the firms' competitiveness

\section{Research Model and Research Hypotheses}

The following figure illustrates the research Independent and dependent variable:

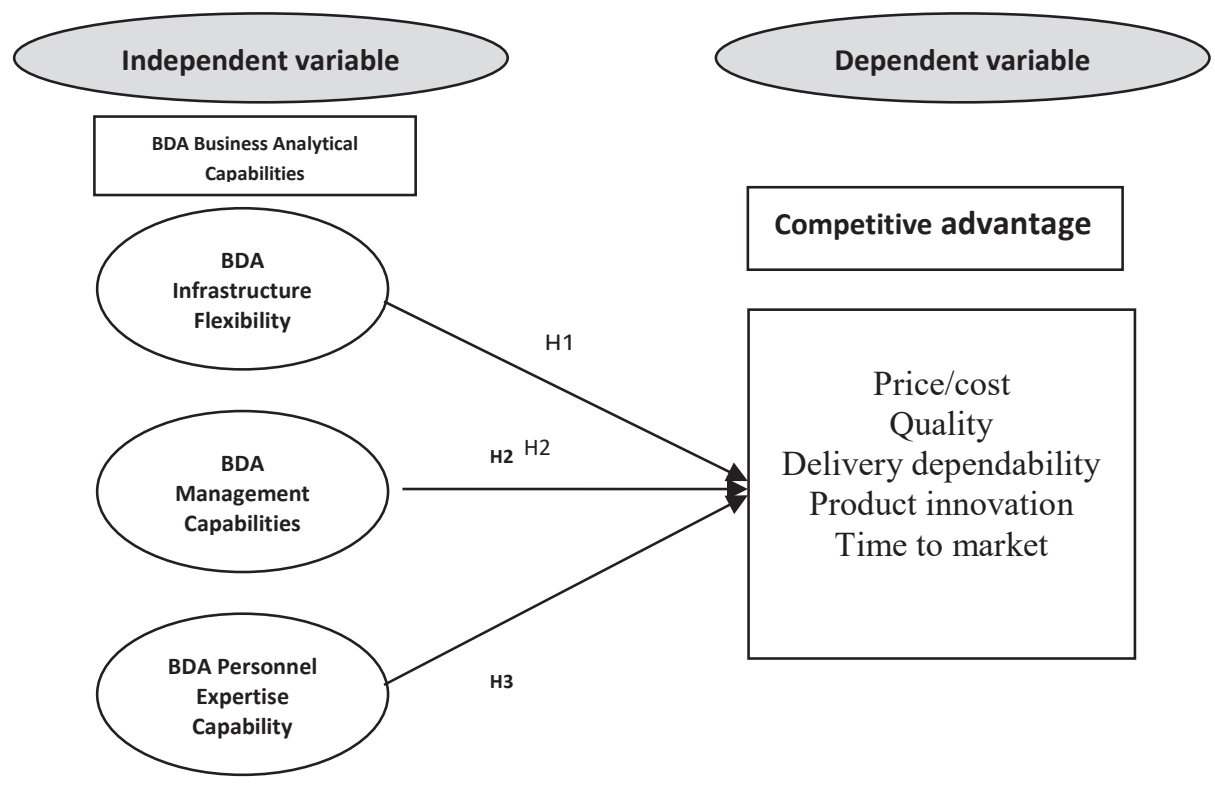

Figure 1. Research Model Source: prepared by the researcher

This study suggests testing the impact of BDA capabilities on the competitive advantages as shown in figure (1); therefore, the following main null hypothesis was formulated:

\section{HO: BDA capabilities have no significant positive impact on competitive advantage}

And the following sub null hypotheses:

- H01: BDA infrastructure Flexibility has no significant positive impact on competitive advantage.

- H02: BDA management capabilities have no significant positive impact on competitive advantage.

- H03: BDA Personnel Expertise Capability has no significant positive impact on competitive advantage.

\section{Questionnaire, Scaling}

This study adopted the questionnaire-based survey method; the survey questionnaire used in the study consists of previously published multi-item scales. The study used two questionnaires; one for IT employees to investigate the independent variable BDA capabilities, and the other one for sales and marketing 
employees to investigate the dependent variable competitive advantage. The first survey: BDA capability indicators were adopted from Kim research (Kim, Shin, \& Kwon, 2012), the second survey: competitive advantages Indicators were adopted from Suhong Li research (Suhong, Nathan \&Rao,2004). All the constructs in the model were measured using 5-point Likert scales (strongly disagree - strongly agree).

\section{Population and Sampling and Data Collection}

\section{First: The Population for the Study}

The population for the study consists of Etisalat Egypt employees (total number $=5645$ ).

\section{Second: The Research Sample}

The research has two samples:

a- First Sample: the research targeted the employees in the big data analytics department to distribute the big data analytics capabilities survey. The number of employees in this department is 200 employees. To identify the sample, a random stratified multi-sector sample was used and the size was determined according to the statistical and non-statistical methods. The sample number is 50 items, which represents $25 \%$ of employees' numbers.

b- Second Sample: The research targeted Top and middle managerial levels employees from all departments for the competitive advantage survey. The number of company employees is 5645 without sales outsourcing a random stratified multi-sector sample was used and the size of the sample was determined by using the formula:

The sample size for the population proportion

$$
n=p(1-p)(Z / E)^{2}
$$

Three items need to be specified:

- The desired level of confidence.

- The margin of error in the population proportion.

- An estimate of the population proportion. (Lind; Marchal \& Wathen, 2012)

1- The used level of confidence is $95 \%$ which it's $Z=1.96$.

2- The margin of error in the population is 0.05 .

3- The estimation of the population proportion assumed (P) $50 \%$.

\section{The Formula will be:}

$0.5(1-0.5)(1.96 / 0.05)^{2}=384 \simeq 385$

According to the previous formula, the second sample number is 400 employees, to cover the probability of not responding for some of the sample items.

Surveys were placed on a survey creator website, the link was sent to the employees and data was filled and collected back, 25 responses for the big data analytics survey and 282 responses for the competitive advantage survey were received back, which represent $50 \%$ and $70.5 \%$ responses were complete and valid to be used.

\section{Data Analysis}

\section{Data Handling and Treatment}

While the statistical analysis and methods that used to answer the questions and hypotheses of the research, the following had been presented: 


\begin{tabular}{|c|c|c|}
\hline The Test & The Type Of Test & Using Rationing \\
\hline ALPHACRONBACH & Nonparametric test. & To measure the reliability and validity of collected data. \\
\hline $\begin{array}{l}\text { Descriptive Statistics: Frequency tables, Mean, } \\
\text { Standard deviation, Coefficient of variation. }\end{array}$ & $\begin{array}{l}\text { Descriptive para- } \\
\text { metric test. }\end{array}$ & To clarify the characteristics of the sample items. \\
\hline Pearson Correlation coefficient & $\begin{array}{l}\text { Inductive Parametric } \\
\text { test. }\end{array}$ & $\begin{array}{l}\text { For determining the correlation relation between every two } \\
\text { variables. (Independent and dependent variables). }\end{array}$ \\
\hline Simple Regression & Parametric test. & To measure the impact of one variable on another variable. \\
\hline $\begin{array}{l}\text { Multiple Regression analysis (using Step- } \\
\text { wise) }\end{array}$ & Parametric test. & $\begin{array}{l}\text { To measure the impact of more than the independent variable } \\
\text { on more than the dependent variable. Besides clarifying the } \\
\text { relative importance for each variable as regards its impact. }\end{array}$ \\
\hline
\end{tabular}

This study is divided into 2 main surveys:

1- First survey: Big data analytics capabilities

2- Second survey: Competitive advantage

\section{Procedures and Methods of the Statistical Analysis:}

Following the researcher questions the following procedures for the statistical analysis have been used:

\section{A- Data Filling Processing}

It was ensured the completeness and validity of the data for the statistical analysis. Statistical Package for Social Sciences (SPSS) ver. (20) used for data analysis

A quick evaluation of the five- Likert Scale used is as follows:

$\begin{array}{ccccc}\text { Agree } & \text { Neutral } & \text { Disagree } & \text { Strong disagree } & \text { Strong agree } \\ 5 & 4 & 3 & 2 & 1\end{array}$

\section{B- Study of the Research Hypotheses}

\section{A detailed explanation of each survey:}

\section{1- Big Data Analytics Capabilities Survey X Includes Two Sections as Follows: Section One:}

Independent variable: "Big Data Analytics Capabilities" X consists of 3 dimensions as follows:

- The BDA Infrastructure Flexibility Dimension x1 consists of 3 Dimension

- BDA Management Capabilities Dimension x 2 consists of 5 Dimension

- The BDA personnel Expertise Capability Dimensionx3 consists of 3 Dimension

\section{Section Two:}

Demographic data including

$$
\text { - Education - Age -Managerial Level }
$$

\section{Reliability and Validity:}

To check the reliability the coefficient "Alpha Cronbach" is used to measure the stability of the answer for the total dimensions of "Big Data Analytics Capabilities", with stability coefficient for the total sample of (0.861) that indicates a high degree of validity for the study sample which was reflected also by its square root coefficient that is equal (0.927).

Table 1. Reliability and Validity for the dimensions "Big Data Analytics Capabilities" by using Cronbach's Alpha coefficient"

\begin{tabular}{|c|c|c|c|}
\hline variable & Dimensions & Reliability & Validity \\
\hline Total $\mathrm{x} 1$ & The BDA : Infrastructure Flexibility & 0.805 & 0.897 \\
\hline Total $\times 2$ & BDA Management Capabilities & 0.748 & 0.864 \\
\hline Total x3 & The BDA Personnel Expertise Capability & 0.873 & 0.934 \\
\hline Total sam & ple: Big Data Analytics Capabilities & 0.861 & 0.927 \\
\hline
\end{tabular}


The reliability coefficient (Cronbach's Alpha) of 0.60 or higher is considered adequate. Overall, all constructs have statistically acceptable ranges for observed items' reliability and validity level in terms of Cronbach's Alpha coefficient values.

Table 2. Internal Consistency with Pearson Coefficient of Correlation Dimension Independent Variables "Big Data Analytics Capabilities (BDAC)"

\begin{tabular}{|c|c|c|c|c|c|}
\hline \multicolumn{2}{|c|}{$\begin{array}{c}\text { Dimension x1 } \\
\text { Infrastructure Flexibility }\end{array}$} & \multicolumn{2}{|c|}{$\begin{array}{c}\text { Dimension } \times 2: \\
\text { Management Capabilities } \\
\end{array}$} & \multicolumn{2}{|l|}{$\begin{array}{c}\text { Dimension x3: } \\
\text { Personnel Expertise Capability }\end{array}$} \\
\hline Dimension & $r$ & Dimension & $r$ & Dimension & $r$ \\
\hline a-Connectivity & $0.785^{* *}$ & a-Planning & $0.853^{* *}$ & a-BDA Technical Knowledge & $0.717^{* *}$ \\
\hline b-Compatibility & $0.538^{*}$ & b- Coordinating & $0.612^{* *}$ & b- BDA Technology Management Capability & $0.547^{* *}$ \\
\hline \multirow[t]{3}{*}{ c- Modularity } & $0.804^{* *}$ & c- Organizing & $0.526^{*}$ & c- BDA Business Knowledge & $0.650^{* *}$ \\
\hline & & d-Leading & $0.835^{* *}$ & & \\
\hline & & e-Controlling & $0.741^{* *}$ & & \\
\hline
\end{tabular}

Dimension $(x 1)$ “The BDA: Infrastructure Flexibility": The Correlation coefficients are between $(0.538,0.804)$ which indicate the validity and consistency of the study tools. Dimension ( $x 2)$ "BDA Management Capabilities": The Correlation coefficients are between $(0.526,0.853)$ which indicates the validity and consistency for the study tools. Dimension (x3) "The BDA Personnel Expertise Capability": The Correlation coefficients are between $(0.547,0.717)$ which indicate the validity and consistency for the study tools.
Table 3. Frequency distribution of the variable Age

\begin{tabular}{|c|c|c|c|c|}
\hline \multicolumn{5}{|c|}{ Demographic date } \\
\hline Number & 1-Age group years & Frequency & present & Rank \\
\hline 1 & From $30-40$ years old. & 16 & 25.8 & 2 \\
\hline 2 & From $41-50$ years old. & 36 & 58.1 & 1 \\
\hline 3 & More than 50 years old. & 10 & 16.1 & 3 \\
\hline & Total & 62 & 100 & - \\
\hline \multicolumn{5}{|c|}{ 2-Education } \\
\hline 1 & College qualification (diploma/certificate) & 0 & 0 & 3 \\
\hline 2 & Undergraduate degree & 54 & 87.1 & 1 \\
\hline 3 & Postgraduate degree (Master/Ph.D.) & 8 & 12.9 & 2 \\
\hline & Total & 62 & 100 & - \\
\hline \multicolumn{5}{|c|}{ 3-Managerial Level } \\
\hline 1 & Top Level Management. & 8 & 12.9 & 2 \\
\hline 2 & Middle-Level Management. & 54 & 87.1 & 1 \\
\hline & Total & 62 & 100 & - \\
\hline
\end{tabular}

Big Data Analytics Capabilities $(X)$ consists of 3 dimensions:

1- The BDA Infrastructure Flexibility Dimension $x 1$ consists of 3 Dimensions: as follows:

Table 4. Descriptive Statistics (Mean, Std. and Coefficient of Variation) for Dimension “Infrastructure Flexibility“ $x 1$

\begin{tabular}{|c|c|c|c|c|}
\hline Items & Mean & Std. & c.v. & Rank \\
\hline \multicolumn{5}{|l|}{ a- Connectivity } \\
\hline $\begin{array}{l}\text { 1-Compared to competitors within our industry, our organization has the foremost available } \\
\text { analytics systems. }\end{array}$ & 3.71 & 0.94 & 25.55 & 3 \\
\hline $\begin{array}{l}\text { 2-All our offices (remote, branch, and mobile) are connected to the central office for sharing } \\
\text { analytics insights. }\end{array}$ & 4.79 & 0.41 & 8.56 & 1 \\
\hline 3-Our organization utilizes open system network mechanisms to boost analytics connectivity. & 3.97 & 0.80 & 20.38 & 2 \\
\hline Mean Average: a & 4.15 & 0.50 & 12.13 & - \\
\hline \multicolumn{5}{|l|}{ b- Compatibility } \\
\hline 4-Software applications are easily used across multiple analytics platforms. & 4.71 & 0.45 & 9.72 & 2 \\
\hline 5-Our user interfaces provide transparent access to all platforms. & 3.79 & 1.02 & 27.07 & 3 \\
\hline 6-Information is shared seamlessly across our organization, regardless of the location. & 3.92 & 0.27 & 7.02 & 1 \\
\hline Mean Average :b & 4.16 & 0.37 & 9.90 & - \\
\hline \multicolumn{5}{|l|}{ c-Modularity } \\
\hline 7-Reusable software modules are widely used in new system development. & 2.26 & 0.59 & 26.50 & 1 \\
\hline 8-End users utilize object-oriented tools, to create their own applications. & 1.95 & 0.68 & 35.28 & 3 \\
\hline 9-The legacy system within our organization restricts the development processes. & 1.23 & 0.42 & 34.31 & 2 \\
\hline Mean Average :c & 1.81 & 0.27 & 15.13 & - \\
\hline Mean Average: Infrastructure Flexibility & 3.37 & 0.24 & 7.33 & - \\
\hline
\end{tabular}


From the above table, it is clear that:

The trend of the sample for "Infrastructure Flexibility" indicates that it is towards the (Agreement) with a mean of (3.37) with a coefficient of variation (7.33\%). Connectivity:

The trend of the sample for "Connectivity" indicates that it is towards the (Agreement) with a mean of (4.15) with a coefficient of variation (12.13\%). The most agreeable statements are all our offices (remote, branch and mobile) are connected to the central office for sharing analytics insights) with coefficients of variation $(8.56 \%)$, the least agreeable statements are (Compared to competitors within our industry, our organization has the foremost available analytics systems) with coefficients of variation ( $25.55 \%)$. Compatibility: The trend of the sample for "Compatibility" indicates that it is towards the (Agreement) with a mean of (4.16) with a coefficient of variation (9.90\%).

The most agreeable statement is (Information is shared seamlessly across our organization, regardless of the location) with coefficients of variation (7.20\%), the least agreeable statements are (Our user interfaces provide transparent access to all platforms) with coefficients of variation (27.07).

Modularity: The trend of the sample for "Modularity" indicates that it is towards the (disagreement) with a mean of (1.81) with a coefficient of variation (15.13\%).

The most agreeable statement is (Reusable software modules are widely used in new system development) with coefficients of variation (26.50\%), the least agreeable statements are (End users utilize object-oriented tools, to create their applications) with coefficients of variation (35.28\%).

\section{BDA Management Capabilities Dimension x2 Consists of 5 Dimensions: as Follows:}

Table 5. Descriptive Statistics (Mean, Std. and Coefficient of Variation) for Dimension "Management Capabilities" x2

\begin{tabular}{|c|c|c|c|c|}
\hline Items & Mean & Std. & c.v. & Rank \\
\hline \multicolumn{5}{|l|}{ a-Planning } \\
\hline 10-We perform business analytics planning processes in systematic ways. & 3.74 & 1.08 & 29.01 & 3 \\
\hline 11- We enforce adequate plans for the utilization of business analytics. & 3.96 & 1.03 & 28.02 & 2 \\
\hline 12-We frequently adjust business analytics plans to better adapt to the changing conditions. & 3.50 & 0.80 & 23.00 & 1 \\
\hline Mean Average: a & 3.64 & 0.79 & 21.90 & - \\
\hline \multicolumn{5}{|l|}{ b- Coordinating } \\
\hline $\begin{array}{l}\text { 13- In our organization, business analysts and line people meet regularly to discuss important } \\
\text { issues. }\end{array}$ & 2.00 & 0.51 & 25.60 & 2 \\
\hline 14- In our organization, business analysts and line people coordinate their efforts harmoniously. & 2.10 & 0.50 & 23.95 & 1 \\
\hline $\begin{array}{l}\text { 15- In our organization, information is widely shared between business analysts and line people } \\
\text { so that those who make decisions or perform jobs have access to all available know-how. }\end{array}$ & 2.23 & 0.75 & 33.90 & 3 \\
\hline Mean Average :b & 2.10 & 0.38 & 18.29 & - \\
\hline \multicolumn{5}{|l|}{ c-Organizing } \\
\hline 16-The responsibility of business analysts is very clear to all the concerning parts. & 3.85 & 0.35 & 9.22 & 1 \\
\hline 17-There is balancing between the responsibility of the business analysts and their authorities. & 3.02 & 0.68 & 22.81 & 4 \\
\hline 18-The organizational structure relies heavily on the teamwork approach. & 3.65 & 0.88 & 24.36 & 5 \\
\hline 19-The organizational structure able to meet the internal and external challenges. & 2.34 & 0.47 & 20.38 & 3 \\
\hline $\begin{array}{l}\text { 20-The communication channels are very clear between the business analysts and the other con- } \\
\text { cerning parts. }\end{array}$ & 2.06 & 0.24 & 12.04 & 2 \\
\hline Mean Average :c & 2.98 & 0.25 & 8.61 & - \\
\hline \multicolumn{5}{|l|}{ d-Leading } \\
\hline 21- We Communicates the vision, mission, and direction & 2.27 & 0.45 & 19.82 & 2 \\
\hline 22- We Motivate, inspire and energize employees to overcome barriers to change & 3.32 & 0.47 & 14.19 & 1 \\
\hline $\begin{array}{l}\text { 23- We Promote useful and dramatic changes, such as new products or approaches to improving } \\
\text { labor relations }\end{array}$ & 2.29 & 0.45 & 20 & 3 \\
\hline Mean Average :d & 2.62 & 0.24 & 9.21 & - \\
\hline \multicolumn{5}{|l|}{ e-Controlling } \\
\hline 24- We constantly monitor the performance of the analytics function. & 3.92 & 0.87 & 22.30 & 4 \\
\hline 25- Our analytics department is clear about its performance criteria. & 2.29 & 0.45 & 20.00 & 3 \\
\hline 26-There is a common understanding, about the criteria, as regards its fairness. & 3.76 & 0.43 & 11.49 & 2 \\
\hline
\end{tabular}




\begin{tabular}{|c|c|c|c|c|}
\hline Items & Mean & Std. & c.v. & Rank \\
\hline 27- There is a common understanding, about the easy way to apply the criteria. & 3.58 & 0.86 & 24.02 & 5 \\
\hline 28- Our company is better than competitors in reducing costs within a business process. & 4.84 & 0.37 & 7.67 & 1 \\
\hline Mean Average :e & 3.67 & 0.29 & 8.02 & - \\
\hline Mean Average : Management Capabilities & 3.01 & 0.23 & 7.76 & - \\
\hline
\end{tabular}

From the above table, it is clear that:

The trend of the sample for "Management Capabilities" indicates that it is towards the (neutral) with a mean of (3.01) with a coefficient of variation (7.76\%). Planning: The trend of the sample for "Planning" indicates that it is towards the (Agreement) with a mean of (3.64) with a coefficient of variation (21.90\%). The most agreeable statement is (We frequently adjust business analytics plans to better adapt with the changing conditions) with coefficients of variation (23.00\%), the least agreeable statements are (We perform business analytics planning processes in systematic ways) with coefficients of variation (29.01\%).

Coordinating: The trend of the sample for "Coordinating" indicates that it is towards the (disagreement) with a mean of (2.10) with a coefficient of variation (18.29\%).

The most agreeable statements are (In our organization, business analysts and line people coordinate their efforts harmoniously) with coefficients of variation (23.95\%), the least agreeable statements are (In our organization, information is widely shared between business analysts and line people so that those who make decisions or perform jobs have access to all available know-how) with coefficients of variation (33.90\%).

Organizing: The trend of the sample for "Organizing" indicates that it is towards the (neutral) with a mean of (2.98) with a coefficient of variation (8.61\%).

The most agreeable statement is (The responsibility of business analysts is very clear to all the concerning parts) with coefficients of variation (9.22\%), the least agreeable statements is (The organizational structure relies heavily on the teamwork approach) with coefficients of variation (24.36\%). Leading: The trend of the sample for "Leading" indicates that it is towards the (neutral) with a mean of (2.62) with a coefficient of variation (9.21\%). The most agreeable statements are (We Motivate, inspire and energize employees to overcome barriers to change) with coefficients of variation (14.19\%), the least agreeable statements are (We Promote useful and dramatic changes, such as new products or approaches to improving labor relations) with coefficients of variation (20.00\%). Controlling: The trend of the sample for "Controlling" indicates that it is towards the (Agreement) with a mean of (3.67) with a coefficient of variation (8.02\%).

The most agreeable statements are (Our company is better than competitors in reducing cost within a business process) with coefficients of variation (7.67\%), the least agreeable statements are (There is a common understanding, about the easy way to apply the criteria) with coefficients of variation (24.02\%).

\section{The BDA Personnel Expertise Capability Dimension x3 Consists of 3 Dimensions: as Follows:}

From table (6), it is clear that:

The trend of the sample for "personnel Expertise Capability" indicates that it is towards the (Agreement) with a mean of (4.22) with a coefficient of variation (3.24\%).

Technical Knowledge: The trend of the sample for "Technical Knowledge" indicates that it is towards the (Agreement) with a mean of (3.93) with a coefficient of variation (5.05\%). The most agreeable statements are (Our analytics personnel is very capable in terms of programming skills) with coefficients of variation (6.29\%), the least agreeable statements are (Our analytics personnel is very capable in decision support systems) with coefficients of variation (12.04\%). 
Technology Management Capability: The trend of the sample for "Technology Management Capability" indicates that it is towards the (strong Agreement) with a mean of (4.74) with a coefficient of variation (5.61\%).

The most agreeable statements are (Our analytics personnel is very knowledgeable about the critical factors for the success of our organization) with coefficients of variation (7.99\%), the least agreeable statements are (Our analytics personnel show superior ability to learn new technologies) with coefficients of variation (10.37\%).

Business Knowledge: The trend of the sample for "Business Knowledge" indicates that it is towards the (agreement) with a mean of (4.00) with a coefficient of variation (4.59\%). The most agreeable statements are (Our analytics personnel is very capable in interpreting business problems and developing appropriate solutions) with coefficients of variation (7.32\%), the least agreeable statements are (Our analytics personnel is very knowledgeable about business functions) with coefficients of variation (13.07\%).

Table 6. Descriptive Statistics (Mean, Std. and Coefficient of Variation) for Dimension “Personnel Expertise Capability" $x 3$

\begin{tabular}{lcccc}
\hline Items & Mean & Std. & c.v. & Rank \\
\hline a-Technical Knowledge & & & & \\
\hline 29- Our analytics personnel are very capable in terms of programming skills & 3.94 & 0.24 & 6.29 & 1 \\
\hline 30- Our analytics personnel are very capable in terms of managing project life cycles. & 3.90 & 0.29 & 7.64 & 2 \\
\hline 31- Our analytics personnel are very capable of decision support systems. & 3.97 & 0.47 & 12.04 & 3 \\
\hline Mean Average: a & 3.93 & 0.19 & 5.05 & - \\
\hline b-Technology Management & & & & \\
\hline 32- Our analytics personnel show a superior understanding of technological trends. & 4.76 & 0.46 & 9.83 & 2 \\
\hline 33-. Our analytics personnel show superior ability to learn new technologies. & 4.65 & 0.48 & 10.37 & 3 \\
\hline $\begin{array}{l}\text { 34- Our analytics personnel are very knowledgeable about the critical factors for the } \\
\text { success of our organization. }\end{array}$ & 4.82 & 0.38 & 7.99 & 1 \\
\hline Mean Average: b & 4.74 & 0.26 & 5.61 & - \\
\hline c-Business Knowledge & & & & \\
\hline $\begin{array}{l}\text { 35- Our analytics personnel understand our organization's policies and plans at a very } \\
\text { high level. }\end{array}$ & 4.77 & 0.42 & 8.85 & 2 \\
\hline $\begin{array}{l}\text { 36- Our analytics personnel are very capable of interpreting business problems and developing } \\
\text { appropriate solutions. }\end{array}$ & 4.85 & 0.35 & 7.32 & 1 \\
\hline $\begin{array}{l}\text { 37- Our analytics personnel are very knowledgeable about business functions. } \\
\text { 38- Our analytics personnel are very knowledgeable about the business environment. }\end{array}$ & 3.23 & 0.42 & 13.07 & 4 \\
\hline Mean Average :c & 4.00 & 0.37 & 11.74 & 3 \\
\hline Mean Average: personnel Expertise Capability & 4.22 & 0.13 & 3.24 & - \\
\hline
\end{tabular}

\section{2- Competitive Advantage Survey Y Includes Two Sections as Follows:}

Section One: Dependent Variable: “Competitive advantage" $Y$ consists of 5 dimensions as follows:

- Price/cost y1dimension consists of two statements.

- Quality y2 dimension consists of three statements.

- Delivery dependability y3 dimension consists of three statements.

- Product Innovation y4 dimension consists of three statements.

- Time to Market y5 dimension consists of three statements.

\section{Section Two: Demographic Date Including:}

- Education: - Age: -Managerial Level

Table 7. Reliability and Validity for the dimensions "Competitive advantage" by using Cronbach's Alpha coefficient"

\begin{tabular}{lcc}
\hline \multicolumn{1}{c}{ Dimensions } & Reliability & Validity \\
\hline Total y1:-Price / cost & 0.813 & 0.901 \\
\hline Total y2: Quality & 0.790 & 0.889 \\
\hline Total y3: Delivery dependability & 0.742 & 0.861 \\
\hline Total y4: Product Innovation & 0.869 & 0.932 \\
\hline Total y5:-Time to Market & 0.751 & 0.867 \\
\hline Total sample: Competitive advantage & 0.834 & 0.913 \\
\hline
\end{tabular}




\section{Measure for the Internal Consistency}

From table (8), it is clear that: The correlation coefficients between each of the Dimension's score in the total dimensions is consistent with its total score to which it belongs, where the first column reflects the "number on its dimensions and the second column is the correlation coefficients for each dimension.

Dimension (Competitive advantage): The correlation coefficients are computed for each of the dimensions' scores in the total dimensions with its total score, at the level of significance less than (0.05). The Correlation coefficients are between $(0.541,0.859)$ which indicates the validity and consistency for the study tools.
Table 8. Internal consistency with Pearson coefficient of correlation Dimension Independent Variables “Competitive advantage

\begin{tabular}{lc}
\hline \multicolumn{1}{c}{ Dimension } & $\mathbf{r}$ \\
\hline 1-Price / cost & $0.629^{* *}$ \\
\hline 2- Quality & $0.541^{* *}$ \\
\hline 3 Delivery dependability & $0.859^{* *}$ \\
\hline 4- Product Innovation & $0.745^{* *}$ \\
\hline 5 -Time to Market & $0.718^{* *}$ \\
\hline${ }^{* *}$ Significant level $(0.01)$ &
\end{tabular}

\section{General Demographic Data: Descriptive Measures (Frequency Tables)}

Competitive advantage ' $y$ ' consists of 5 dimensions:

From the above table, it is clear that: The trend of the sample for "Competitive advantage" indicates that it is towards the (Agreement) with a mean of (3.89) with a coefficient of variation $(11.82 \%)$.

Price/Ccost: The trend of the sample for "Price/cost" indicates that it is towards the (Strong Agreement) with a mean of (4.50) with a coefficient of variation (13.12\%). The most agreeable statements are (We offer competitive prices to our customers) with coefficients of variation (16.75\%), the least agreeable statements are (We can offer prices as low or lower than our competitors) with coefficients of variation (17.90\%).

Quality: The trend of the sample for "Quality" indicates that it is towards the (neutral) with a mean of (3.42) with a coefficient of variation (13.05\%). The most agreeable statements are (We can compete based on quality) with coefficients of variation (15.34\%), the least agreeable statements are (We offer high-quality services to our customer) with coefficients of variation (23.70\%).

Delivery Dependability: The trend of the sample for "Delivery dependability" indicates that it is towards the (Agreement) with a mean of (3.98) with a coefficient of variation (9.43\%). The most agreeable statements are (We provide dependable service delivery) with coefficients of variation (7.32\%), the least agreeable statements are (We deliver customer services on time) with coefficients of variation (18.50\%).

Product Innovation: The trend of the sample for "Product Innovation" indicates that it is towards the (Agreement) with a mean of (4.34) with a coefficient of variation (9.81\%). The most agreeable statement is (We modify our services offerings to meet client needs) with coefficients of variation (6.60\%), the least agreeable statements are (We respond well to customer demand for "new" features) with coefficients of variation (20.00\%).

Time to Market: The trend of the sample for "Time to Market" indicates that it is towards the (neutral) with a mean of (2.83) with a coefficient of variation (7.75\%). The most agreeable statements are (We are first in the market in introducing new services) with coefficients of variation (12.62\%), the least agreeable statements are (We have fast product development) with coefficients of variation (19.95\%).

\section{Hypothesis Testing:}

Main Hypothesis:

HO: BDA capabilities $X$ have no significant positive impact on competitive advantage $Y$.

1- $\mathrm{HO}_{1}$ : BDA infrastructure Flexibility $\mathrm{x} 1$ has no significant positive impact on competitive advantage.

2- $\mathrm{H}_{2}$ : BDA management capabilities $x 2$ have no significant positive impact on competitive advantage.

3- $\mathbf{H}_{3}$ : BDA Personnel Expertise Capability $x 3$ has no significant positive impact on competitive advantage. 
Table 9. Frequency Distribution of the Demographic Data

\begin{tabular}{|c|c|c|c|c|}
\hline & Variables & Frequency & present & Rank \\
\hline No. & \multicolumn{4}{|c|}{ 1-Age group years } \\
\hline 1 & Less than 30 years old & 31 & 9.8 & 4 \\
\hline 2 & From 30-40 years old. & 135 & 42.9 & 1 \\
\hline 3 & From $41-50$ years old. & 104 & 33.0 & 2 \\
\hline 4 & More than 50 years old. & 45 & 14.3 & 3 \\
\hline & Total & 315 & 100 & - \\
\hline \multicolumn{5}{|c|}{ 2-Education } \\
\hline 1 & Secondary school qualification & 29 & 9.2 & 4 \\
\hline 2 & $\begin{array}{l}\text { College qualification (di- } \\
\text { ploma/certificate) }\end{array}$ & 45 & 14.3 & 2 \\
\hline 3 & Undergraduate degree & 206 & 65.4 & 1 \\
\hline 4 & $\begin{array}{l}\text { Postgraduate degree (Mas- } \\
\text { ter/Ph.D.) }\end{array}$ & 35 & 11.1 & 3 \\
\hline & Total & 315 & 100 & - \\
\hline \multicolumn{5}{|c|}{ 3-Managerial Level } \\
\hline 1 & Top Level Management. & 36 & 11.4 & 2 \\
\hline 2 & Middle-Level Management. & 279 & 88.6 & 1 \\
\hline & Total & 315 & 100 & - \\
\hline
\end{tabular}

The Statistical Method Used: The Correlation Coefficient of Pearson

From the table (11) it is clear:

There is a significant positive relationship between (Big Data Analytics Capabilities and Competitive advantage), at a p-value level of significantly less than (.01).

\section{Main Hypothesis:}

HO: Big Data Analytics Capabilities have no significant positive impact on Competitive advantage

From the table (12):

- We found that the independent variable (Big Data Analytics Capabilities $x$ ) explains with value $\left(R^{2}\right)$ by (\%67.8), of the total change in the dependent variable (Competitive advantage) $y$, Using selection (t. test) equal (10.027), with significance level less than (0.01).

- We accepted the alternative hypothesis that there is a statistically significant impact of "Big Data Analytics Capabilities x "on Competitive advantage " $y$ "

a- We found that the independent variable (Big Data Analytics Capabilities $x)$ explains with value $\left(R^{2}\right)$ by $(\% 48.3)$ of the total change in the dependent variable (Price/cost) $y 1$, Using selection (t. test) equal (10.683), with significance level less than (0.01).

b- We found that the independent variable (Big Data Analytics Capabilities $x$ ) explains with val-
Table 10. Descriptive Statistics (Mean, Std. and Coefficient

\begin{tabular}{|c|c|c|c|c|}
\hline Items & Mean & Std. & c.v. & Rank \\
\hline \multicolumn{5}{|l|}{ a-Price / cost } \\
\hline 1- We offer competitive prices to our customers. & 4.58 & 0.76 & 16.75 & 1 \\
\hline $\begin{array}{l}\text { 2- We can offer prices as low or lower } \\
\text { than our competitors. }\end{array}$ & 4.43 & 0.79 & 17.90 & 2 \\
\hline Mean Average: a & 4.50 & 0.59 & 13.12 & - \\
\hline \multicolumn{5}{|l|}{ b-Quality } \\
\hline 3-We are able to compete based on quality. & 3.26 & 0.50 & 15.34 & 1 \\
\hline 4- We offer highly reliable services. & 4.03 & 0.76 & 19.03 & 2 \\
\hline 5-We offer high-quality services to our customers. & 2.97 & 0.70 & 23.70 & 3 \\
\hline Mean Average $: b$ & 3.42 & 0.44 & 13.05 & - \\
\hline \multicolumn{5}{|l|}{ c-Delivery dependability } \\
\hline 6-We deliver the kind of needed products. & 3.95 & 0.75 & 18.96 & 3 \\
\hline 7-We deliver customer services on time. & 4.00 & 0.74 & 18.50 & 2 \\
\hline 8- We provide dependable service delivery. & 4.00 & 0.29 & 7.32 & 1 \\
\hline Mean Average :c & 3.98 & 0.37 & 9.43 & - \\
\hline \multicolumn{5}{|l|}{ d-Product Innovation } \\
\hline 9- We provide customized services. & 4.14 & 0.69 & 16.86 & 2 \\
\hline $\begin{array}{l}\text { 10- We modify our services offerings to } \\
\text { meet client needs. }\end{array}$ & 4.88 & 0.32 & 6.60 & 1 \\
\hline $\begin{array}{l}\text { 11- We respond well to customer de- } \\
\text { mand for "new" features. }\end{array}$ & 4.00 & 0.80 & 20.00 & 3 \\
\hline Mean Average : $d$ & 4.34 & 0.42 & 9.81 & - \\
\hline \multicolumn{5}{|l|}{ e-Time to Market } \\
\hline $\begin{array}{l}\text { 12- We are first in the market in intro- } \\
\text { ducing new services. }\end{array}$ & 3.21 & 0.40 & 12.62 & 1 \\
\hline 13-We have fast product development. & 2.22 & 0.43 & 19.59 & 3 \\
\hline $\begin{array}{l}\text { 14-We have time-to-market lower than } \\
\text { our competitors. }\end{array}$ & 3.10 & 0.59 & 19.19 & 2 \\
\hline Mean Average :e & 2.83 & 0.21 & 7.75 & - \\
\hline Mean Average : Competitive advantage & 3.89 & 0.46 & 11.82 & - \\
\hline
\end{tabular}

Table 11. Correlation between "Big Data Analytics Capabilities and Competitive advantage "by using Pearson correlation

\begin{tabular}{lc}
\hline \multicolumn{2}{c}{$\begin{array}{c}\text { Dimensions: Big Data } \\
\text { Analytics Capabilities x }\end{array}$} \\
\hline y1-Price / cost & $0.695^{* *}$ \\
\hline y2- Quality & $0.750^{* *}$ \\
\hline y3 Delivery dependability & $0.716^{* *}$ \\
\hline y4- Product Innovation & $0.491^{* *}$ \\
\hline y5 -Time to Market & $0.535^{* *}$ \\
\hline Competitive advantages & $0.824^{* *}$ \\
\hline ** Significant level 0.01
\end{tabular}
of Variation) for dimension "Competitive advantage " $Y$ 
ue $\left(R^{2}\right)$ by (\%56.2) of the total change in the dependent variable (Quality) y2, Using selection (t. test) equal (12.523), with significance level less than (0.05).

c- We found that the independent variable (Big Data Analytics Capabilities $x$ ) explains with value $\left(\mathrm{R}^{2}\right)$ by (\%51.2) of the total change in the dependent variable (Delivery dependability) y3, Using selection (t. test) equal (11.320), with significance level less than (0.01).

$\mathrm{d}$ - We found that the independent variable (Big Data Analytics Capabilities $\mathrm{x}$ ) explains with value $\left(R^{2}\right)$ by (\%24.1) of the total change in the dependent variable (Product Innovation) y4, Using selection (t. test) equal (6.229), with significance level less than (0.01).

e- We found that the independent variable (Big Data Analytics Capabilities $x$ ) explains with value $\left(R^{2}\right)$ by (\%28.7) of the total change in the dependent variable (Time to Market) y5, Using selection (t. test) equal (7.001), with significance level less than (0.01).

Table 12. The Effect of Big Data Analytics Capabilities X on Competitive Advantage Y by Using Linear Regression

\begin{tabular}{|c|c|c|c|c|c|c|c|}
\hline Independent variable & Path & dependent variables & $\beta$ & Std. Error & $\mathbf{t}$ & Sig. & $\mathbf{R}^{2}$ \\
\hline x-Big Data Analytics Capabilities & $\rightarrow$ & y1-Price / cost & 0.695 & 0.05 & 10.683 & $0.01^{* *}$ & $48.3 \%$ \\
\hline x-Big Data Analytics Capabilities & $\rightarrow$ & y2- Quality & 0.750 & 0.07 & 12.523 & $0.01^{* *}$ & $56.2 \%$ \\
\hline x-Big Data Analytics Capabilities & $\rightarrow$ & y3 Delivery dependability & 0.716 & 0.06 & 11.320 & $0.01^{* *}$ & $51.2 \%$ \\
\hline x-Big Data Analytics Capabilities & $\rightarrow$ & y4- Product Innovation & 0.491 & 0.15 & 6.229 & $0.01^{* *}$ & $24.1 \%$ \\
\hline x-Big Data Analytics Capabilities & $\rightarrow$ & y5-Time to Market & 0.535 & 0.09 & 7.001 & $0.01^{* *}$ & $28.7 \%$ \\
\hline X-Big Data Analytics Capabilities & $\rightarrow$ & Competitive advantage & 0.842 & 0.04 & 16.038 & $0.01^{* *}$ & $67.8 \%$ \\
\hline
\end{tabular}

From the above, we conclude that the total Independent variable: (Big Data Analytics Capabilities $x$ ) has a significant impact on all dimensions (Competitive advantages y) but in some degrees was the most statistically significant (Quality - Delivery dependability- Price/cost - Time to Market - Product Innovation), according to coefficient $(\beta),(0.750),(0.716),(0.695),(0.535),(0.491)$, respectively.

1- $\mathrm{HO}_{1}$ : Infrastructure Flexibilityx1 has no significant positive impact on Competitive advantage.

Correlation matrix: to the relationship between Infrastructure Flexibility $x 1$ has a positive impact on Competitive advantage

\section{The Statistical Method Used: The Correlation Coefficient of Pearson}

From the table (13) it is clear:

There is a significant positive relationship between (Infrastructure Flexibility x1and Competitive advantage), at a p-value of significance level less than (.01).

From the table (14):

- We founf that the independent variable (Infrastructure Flexibility $x 1)$ explains with value $\left(\mathrm{R}^{2}\right)$ by $(\% 72.9)$, of the total change in the dependent variable (Competitive advantage) $y$, Using selection (t. test) equal (18.125), with significantly less than (0.01).

- We accepted alternative hypothesis that there is a statistically significant impact of "Infrastructure Flexibility x1 "on Competitive advantage " $y$ "

a- We found that the independent variable (Infrastructure Flexibility $x 1)$ explains with value (R2) by (\%52.5) of the total change in the dependent variable (Price/cost) y1, Using selec-
Table 13. Correlation between "Infrastructure Flexibility and Competitive advantage" by using Pearson correlation

\begin{tabular}{lc}
\hline $\begin{array}{l}\text { Dimensions: Infrastruc- } \\
\text { ture Flexibility x1 }\end{array}$ & $r$ \\
\hline y1-Price / cost & $0.725^{* *}$ \\
\hline y2- Quality & $0.770^{* *}$ \\
\hline y3 Delivery dependability & $0.745^{* *}$ \\
\hline y4- Product Innovation & $0.512^{* *}$ \\
\hline y5 -Time to Market & $0.556^{* *}$ \\
\hline Competitive advantage & $0.854^{* *}$ \\
\hline ** Significant level 0.01 & \\
\hline
\end{tabular}


tion (t. test) equal (11.623), with significantly less than (0.01).

b- We found that the independent variable (Infrastructure Flexibility $x 1$ ) explains with value (R2) by (\%59.3) of the total change in the dependent variable (Quality) y2, Using selection ( $\mathrm{t}$. test) equal (13.338), with significantly less than (0.05).

c- We found that the independent variable (Infrastructure Flexibility $x 1$ ) explains with value (R2) by $(\% 55.5)$ of the total change in the dependent variable (Delivery dependability) y3, Using selection (t. test) equal (12.344), with significantly less than (0.01).

$\mathrm{d}$ - We found that the independent variable (Infrastructure Flexibility $\times 1$ ) explains with value (R2) by (\%26.2) of the total change in the dependent variable (Product Innovation) y4, Using selection (t. test) equal (6.582), with significantly less than (0.01).

e- We found that the independent variable (Infrastructure Flexibility $x 1$ ) explains with value $\left(R^{2}\right)$ by (\%30.9) of the total change in the dependent variable (Time to Market) y5, Using selection ( $\mathrm{t}$. test) equal (7.394), with significantly less than (0.01).

Table 14. The effect of infrastructure Flexibility $x 10 n$ Competitive advantage by using Linear Regression

\begin{tabular}{|c|c|c|c|c|c|c|c|}
\hline Independent variable & Path & dependent variables & $\bar{\beta}$ & Std. Error & $\mathbf{t}$ & Sig. & $\mathbf{R}^{2}$ \\
\hline X1-Infrastructure Flexibility & $\rightarrow$ & y1-Price / cost & 0.725 & 0.05 & 11.623 & $0.01^{* *}$ & $52.5 \%$ \\
\hline X1-Infrastructure Flexibility & $\rightarrow$ & y2-Quality & 0.770 & 0.08 & 13.338 & $0.01^{* *}$ & $59.3 \%$ \\
\hline X1-Infrastructure Flexibility & $\rightarrow$ & y3 Delivery dependability & 0.745 & 0.05 & 12.344 & $0.01^{* *}$ & $55.5 \%$ \\
\hline X1-Infrastructure Flexibility & $\rightarrow$ & y4-Product Innovation & 0.512 & 0.10 & 6.582 & $0.01^{* *}$ & $26.2 \%$ \\
\hline X1-Infrastructure Flexibility & $\rightarrow$ & y5 -Time to Market & 0.556 & 0.09 & 7.394 & $0.01^{* *}$ & $30.9 \%$ \\
\hline X1-Infrastructure Flexibility & $\rightarrow$ & Competitive advantage & 0.854 & 0.04 & 18.125 & $0.01^{* *}$ & $72.9 \%$ \\
\hline
\end{tabular}

- Time to Market - Product Innovation), according to coefficient $(\mathcal{\beta}),(0.770),(0.745),(0.725),(0.556),(0.512)$, respectively. ${ }^{* *}$ Significant level $0.01 *$ Significant level 0.05 .

From the above, we conclude that the total Independent variable: (Infrastructure Flexibility x1) has a significant effect on all dimensions (Competitive advantage) but in some degrees the most statistically significant was (Quality - Delivery dependability-Price/cost

2- $\quad \mathrm{H}_{2}$ : Management Capabilities $x 2$ has a positive impact on Competitive advantage.

\section{The Statistical Method Used: The Correlation Coefficient of Pearson}

From table (15) it is clear that:

There is a significant positive relationship between (Management Capabilities $x 2$ and Competitive Advantage), at a p-value of significance level less than (.05).

Table 15. Correlation between "Management Capabilities $x 2$ and Competitive advantage " by using Pearson correlation

\begin{tabular}{lc}
\hline $\begin{array}{c}\text { Dimensions: Manage- } \\
\text { ment Capabilities x2 }\end{array}$ & $\mathbf{r}$ \\
\hline y1-Price / cost & $0.511^{* *}$ \\
\hline y2- Quality & $0.637^{* *}$ \\
\hline y3 Delivery dependability & $0.505^{* *}$ \\
\hline y4- Product Innovation & $0.769^{* *}$ \\
\hline y5 -Time to Market & $0.195^{*}$ \\
\hline Competitive advantage & $0.615^{* *}$ \\
\hline ** Significant level 0.01 & \\
\end{tabular}

Table 16. The Effect of Management Capabilities x2on Competitive Advantage by Using Linear Regression

\begin{tabular}{lccccccc}
\hline \multicolumn{1}{c}{ Independent variable } & Path & dependent variables & $\beta$ & Std. Error & t & Sig. & $\mathrm{R}^{2}$ \\
\hline X2-Management Capabilities & $\rightarrow$ & y1-Price / cost & 0.511 & 0.06 & 6.568 & $0.01^{* *}$ & $26.1 \%$ \\
\hline X2-Management Capabilities & $\rightarrow$ & y2- Quality & 0.637 & 0.08 & 9.132 & $0.01^{* *}$ & $40.6 \%$ \\
\hline X2-Management Capabilities & $\rightarrow$ & y3 Delivery dependability & 0.505 & 0.06 & 6.456 & $0.01^{* *}$ & $25.5 \%$ \\
\hline X2-Management Capabilities & $\rightarrow$ & y4- Product Innovation & 0.769 & 0.06 & 13.282 & $0.01^{* *}$ & $59.1 \%$ \\
\hline X2-Management Capabilities & $\rightarrow$ & y5 -Time to Market & 0.195 & 0.09 & 2.200 & $0.03^{*}$ & $3.8 \%$ \\
\hline X2-Management Capabilities & $\rightarrow$ & Competitive advantage & $\mathbf{0 . 6 1 5}$ & 0.05 & $\mathbf{8 . 6 2 5}$ & $0.01^{* *}$ & $37.9 \%$ \\
\hline
\end{tabular}

** Significance level $0.01,{ }^{*}$ significant level 0.05

From the above table: 
- We found that the independent variable (Management Capabilities $\times 2$ ) explains with value $\left(\mathrm{R}^{2}\right)$ by (\%37.9), of the total change in the dependent variable (Competitive advantage) $y$, Using selection (t. test) equal (8.625), with significance level less than (0.01).

- We accepted alternative hypothesis that there is a statistically significant impact of "Management Capabilities $x 2$ "on Competitive advantage " $y$ "

a- We found that the independent variable (Management Capabilities $\times 2$ ) explains with value (R2) by (\%26.1) of the total change in the dependent variable (Price/cost) y1, Using selection (t. test) equal (6.568), with significance level less than (0.01).

b- We found that the independent variable (Management Capabilities x2) explains with value (R2) by (\%40.6) of the total change in the dependent variable (Quality) y2, Using selection (t. test) equal (9.132), with significance level less than (0.05).

c- We found that the independent variable (Management Capabilities $\times 2$ ) explains with value (R2) by $(\% 25.5)$ of the total change in the dependent variable (Delivery dependability) y3, Using selection (t. test) equal (6.456), with significance level less than (0.01).

$\mathrm{d}$ - We found that the independent variable (Management Capabilities $x 2$ ) explains with value $\left(\mathrm{R}^{2}\right)$ by (\%59.1) of the total change in the dependent variable (Product Innovation) y4, Using selection (t. test) equal (13.282), with significance level less than (0.01).

e- We found that the independent variable (Management Capabilities $\times 2$ ) explains with value (R2) by (\%3.8) of the total change in the dependent variable (Time to Market) y5, Using selection ( $\mathrm{t}$. test) equal (2.200), with significance level less than (0.05).

From the above, we conclude that the total Independent variable: (Management Capabilities x2) has a significant effect on all dimensions (Competitive advantages $y$ ) but the most statistically significant were (Product Innovation - Quality - Price/cost - Delivery dependability - Time to Market), according to a coefficient $(\beta),(0.769),(0.637),(0.511),(0 . \quad$ Table 17 . Correlation between 505), (0.195), respectively.

\section{3- $\mathrm{HO}_{3}$ : Personnel Expertise Capability $\mathrm{x} 3$ has a positive impact on Competitiveadvantage.}

The Statistical Method Used: The Correlation Coefficient of Pearson

From the table (17) it is clear that:

There is a significant positive relationship between (Personnel Expertise $x 3$ and Competitive advantage), at a p-value level of significance less than (.05).

“Personnel Expertise Capability $x 3$ and Competitive advantage " by using Pearson correlation

\begin{tabular}{lc}
\hline \multicolumn{2}{l}{ Dimensions: Personnel } \\
Expertise Capability x3 \\
\hline y1-Price / cost & $0.664^{* *}$ \\
\hline y2- Quality & $0.717^{* *}$ \\
\hline y3 Delivery dependability & $0.698^{* *}$ \\
\hline y4- Product Innovation & $0.590^{* *}$ \\
\hline y5 -Time to Market & $0.444^{*}$ \\
\hline Competitive advantage & $0.792^{* *}$ \\
\hline$* *$ significance level 0.01 &
\end{tabular}

Table 18. The Effect of Personnel Expertise $x 3$ on Competitive Advantage by Using Linear Regression

\begin{tabular}{lcccccccc}
\hline Independent variable & Path & dependent variables & $\beta$ & Std. Error & t & Sig. & $\mathbf{R}^{2}$ \\
\hline X3-Personnel Expertise & $\rightarrow$ & y1-Price / cost & 0.664 & 0.06 & 9.808 & $0.01^{* *}$ & $44.1 \%$ \\
\hline X3-Personnel Expertise & $\rightarrow$ & y2- Quality & 0.717 & 0.08 & 11.351 & $0.01^{* *}$ & $51.4 \%$ \\
\hline X3-Personnel Expertise & $\rightarrow$ & y3 Delivery dependability & 0.689 & 0.05 & 10.505 & $0.01^{* *}$ & $47.5 \%$ \\
\hline X3-Personnel Expertise & $\rightarrow$ & y4- Product Innovation & 0.590 & 0.09 & 8.077 & $0.01^{* *}$ & $34.8 \%$ \\
\hline X3-Personnel Expertise & $\rightarrow$ & y5 -Time to Market & 0.444 & 0.09 & 5.476 & $0.01^{* *}$ & $19.7 \%$ \\
\hline X3-Personnel Expertise & $\rightarrow$ & Competitive advantages & $\mathbf{0 . 7 9 2}$ & $\mathbf{0 . 0 4}$ & 14.319 & $0.01^{* *}$ & $62.7 \%$ \\
\hline ** Significant level 0.01* Significant level0.05 & & & & & &
\end{tabular}

** Significant level $0.01,{ }^{*}$ Significant level 0.05

From the above table : 
- We found that the independent variable (Personnel Expertisex3) explains with value $\left(R^{2}\right)$ by (\%62.7), of the total change in the dependent variable (Competitive advantages) $Y$, Using selection (t. test) equal (14.319), with significance level less than (0.01).

- We accept the alternative hypothesis that there is a statistically significant impact of "Personnel Expertisex 3 "on Competitive advantage " $y$ "

a- We found that the independent variable (Personnel Expertisex3) explains with value $\left(R^{2}\right)$ by (\%44.1) of the total change in the dependent variable (Price/cost) y1, Using selection (t. test) equal (9.808), with significance level less than (0.01).

b- We found that the independent variable (Personnel Expertisex3) explains with value (R2) by (\%51.4) of the total change in the dependent variable (Quality) y2, Using selection (t. test) equal (11.351), with significance level less than (0.05).

c- We found that the independent variable (Personnel Expertisex3) explains with value $\left(R^{2}\right)$ by $(\% 47.5)$ of the total change in the dependent variable (Delivery dependability) $y 3$, Using selection (t. test) equal (), with significance level less than (0.01).

$\mathrm{d}$ - We found that the independent variable (Personnel Expertisex3) explains with value (R2) by (\%34.8) of the total change in the dependent variable (Product Innovation) y4, Using selection (t. test) equal (8.077), with significance level less than (0.01).

e- We found that the independent variable (Personnel Expertisex3) explains with value (R2) by (\%19.7) of the total change in the dependent variable (Time to Market) y5, Using selection (t. test) equal (5.476), with significance level less than (0.05).

From the above, we conclude that the total Independent variable: (Personnel Expertisex3) has a significant effect on all dimensions (Competitive advantages $y$ ) but in some degrees the most statistically significant were (quality - Delivery dependability - Price/cost - Product Innovation - Time to Market), as according by a coefficient $(\beta),(0.717),(0.689),(0.664),(0.590),(0.444)$, respectively.

\section{The Multiple Model Regression}

To study the four Impact of The Independent Variables Big Data Analytics Capabilities x on Competitive advantages $y$

From the above table it is clear that:

\section{1- $\left(R^{2}\right)$ : Coefficient of Determination}

We found that the independent variable effect (Big Data Analytics Capabilities) x (\%73.3) explains the total change in the dependent variable (Competitive advantage) $y$ and the rest is due to random error in the equation, or perhaps the lack of inclusion of other independent variables, that was supposed to be included within the form of the regression model.

\section{2- T. Test:}

Test for the significance of the independent variables.

Using (t.test), we found that the independent, variable, (Infrastructure Flexibility), (Management Capabilities), have a significant effect on the dependent, (Competitive advantage) $y$ the significance level less than (0.05), with value (t) (6.140), (4.169), respectively.

Table (19): Test for the Impact of "Big Data Analytics Capabilities on Competitive advantage" by using Model multiple regression

\begin{tabular}{|c|c|c|c|c|c|c|}
\hline \multirow{2}{*}{ Independent variables } & \multirow{2}{*}{$\beta$} & \multicolumn{2}{|c|}{ t. test } & \multicolumn{2}{|c|}{ F. test } & \multirow{2}{*}{$\mathbf{R}^{2}$} \\
\hline & & Value & Sig. & Value & Sig. & \\
\hline Constant & 0.978 & 6.591 & $0.01^{* *}$ & 109.695 & $.01^{* *}$ & $73.3 \%$ \\
\hline X1-Infrastructure Flexibility & 0.424 & 6.140 & $0.01^{* *}$ & & & \\
\hline X2-Management Capabilities & 0.215 & 4.169 & $0.01^{* *}$ & & & \\
\hline X3-Personnel Expertise Capability & 0.107 & 1.797 & 0.07 & & & \\
\hline
\end{tabular}




\section{3- F. Test:}

Test the total quality of the regression model:

To test the total quality of the model as a whole (F-test) was used, and the value was (109.695), which is significant at a lower level of (0.01), which indicates Competitive Advantage.

\section{4- The Form of the Regression Equation:}

Competitive Advantage $=0.978+0.424$ Infrastructure Flexibility x $1+0.215$ Management Capabilities $x 2$

\section{Results and Recommendations:}

\section{1- Results}

The primary objective of this study was to examine the impact of Big Data Analytics Capabilities on Competitive advantage, the results show that Big data analytics capabilities have a significant impact on competitive advantage. Moreover, it has a significant impact on all dimensions of competitive advantage, but the most statistically significant were (Quality - Delivery dependability- Price/cost - Time to Market - Product Innovation). Independent variable infrastructure Flexibility has a significant effect on all dimensions of Competitive advantage, but the most statistically significant were (Quality - Delivery dependability-Price/cost - Time to Market - Product Innovation). Independent variable management capabilities have a significant effect on all dimensions of Competitive advantages, but the most statistically significant were (Product Innovation - Quality - Price/cost - Delivery dependability - Time to Market). Also, Independent variable Personnel Expertise has a significant effect on all dimensions of Competitive advantages, but the most statistically significant were (quality - Delivery dependability - Price/cost - Product Innovation - Time to Market). Besides, the independent, variables Infrastructure Flexibility and Management Capabilities have a significant effect on the dependent Competitive advantage

\section{2- Recommendations}

Management in the telecommunication sector should take into account that enhancing Big Data capabilities and considering big data as part of their operations can improve their Competitive Advantage and their Performance. Furthermore, Infrastructure Flexibility and Management capabilities were relatively more important than Personnel Expertise between all the dimensions of BDAC, but these differences are small, so all the dimensions should be given the same value in building BDAC. The results also show that the three BDAC components strongly influence firms' competitive advantage which indicates that, to translate BDAC into a competitive advantage, telecommunication managers need to concentrate on infrastructure capability, which includes BDA connectivity, compatibility, and modularity. Besides, Process improvement can significantly impact the profit of corporations and assist in remaining viable. So organizations should reinforce management capabilities to improve product innovation and the quality of services provided by telecommunication companies. 


\section{References}

Alguliyev R. M.; Hajirahimova M. S. (2014). “Big Data"Phenomenon: Challenges and Opportunities", Problems of Information Technology, No.2, pp. 3-16.

- $\quad$ Barton, D. and Court, D. (2012). Making Advanced Analytics Work For You. Harvard Business Review, 90, 78.

- Branfs, K. C. M. A. (2014). "Big Data and Business Intelligence for Management Accountants", Strategic Finance, 95, 64-65.

- Brien, J. O.; Marakas G. and R. Behl. (2010). Management Information Systems. New Delhi: Tata, McGraw Hill Education Private Limited.

- $\quad$ Brynjolfsson, E. and Hitt, L. M. (2000). “Beyond Computation: Information Technology, Organizational Transformation and Business Performance," Journal of Economic Perspectives, Vol. 14, No. 4, pp. 23-48.

- Carr, N. G. (2003). “IT Doesn't Matter”, Harvard Business Review, (81:5), pp. 41-49.

- Chae, H.; C. Koh and Prybutok, V. (2014). “Information Technology Capability and Firm Performance: Contradictory Findings and Their Possible Causes”, MIS Quarterly, Vol. 38, No. 1, pp. 305-326.

- Charles, Vincent and Gherman, Tatiana. (2013). “Achieving Competitive Advantage Through Big Data Strategic Implications", Middle-East Journal of Scientific Research, 16 (8), pp.1069-1074.

- Charles, Vincent and Gherman, Tatiana. (2013). “Achieving Competitive Advantage Through Big Data Strategic Implications", Middle-East Journal of Scientific Research, 16 (8), pp. 1069-1074.

- $\quad$ Chen, M.; Mao, S. and Y. Liu. (2014). Big Data: A Survey. Mobile Networks and Applications 19 (2), pp. 171-209.

- Constantiou, loanna D. and Kallinikos, Jannis. (2015), “New Games, New Rules: Big Data and the Changing Context of Strategy", "Journal of Information Technology", 30 (1). pp. 44-57.

- $\quad$ Cooper, M. and Mell, P. (2012). Tackling Big Data. National Institute of Standards and Technology. Http://csrc.nist.gov/groups/SMA/forum/documents/june2012 presentations/ fcsm_june2012 cooper_mell.pdf

- Davenport, T. H., Barth, P. and Bean, R. (2012). "How`Big Data' is Different”, MIT Sloan Management Review, 54, pp. 43-46.

- Dewan, S. and Andren, F. (2011). "Information Technology and Firm Boundaries: Impact on Firm Risk and Return Performance," Information Systems Research, Vol. 22, No. 2, pp. 369-388.

- Dremel, C.; Overhage, S.; Schlauderer, S. and Wulf, J. (2017). “Towards a Capability Model for Big Data Analytics", In Leimeister, J. M.; Brenner, W. (Hrsg.): Proceedings der 13. International Entagungwirtschafts Informatik WI (2017), St. Gallen, S. 1141-1155

- Fosso Wamba, Samuel \& Akter, Shahriar \& Edwards, Andrew \& Chopin, Geoffrey \& Gnanzou, Denis. (2014). How 'big data' can make big impact: Findings from a systematic review and a longitudinal case study. International Journal of Production Economics. 10.1016/j.ijpe.2014.12.031.

- $\quad$ Fosso, Wamba, S.; Gunasekaran, A.; Akter, S.; Ren, S. Ji-fan.; Dubey, R. \& Childe, S. J. (2017). "Big Data Analytics and Firm Performance: The Effects of Dynamic Capabilities", Journal of Business Research, 70, pp. 356-365.

- Gartner IT Glossary. (2012). Big Data. Http://www.gartner.com/it-glossary/big-data.

- Germann, F.; Lilien, G. L.; Fiedler, L. and Kraus, M. (2014). “Do Retailers Benefit from Deploying Customer Analytics?", Journal of Retailing, 90, pp. 587-593. 
Gobble, M. M. (2013). "Big dData: The Next Big Thing in Innovation", Research-Technology Management, (56: 1), pp. 64-66

- Hagel, J. (2015). "Bringing Analytics to Life", Journal of Accountancy, 219, pp. 24-25.

- Hernandez, Julio. (2013). Building an Analytics-driven Organization Organizing, Governing, Sourcing and Growing Analytics Capabilities in CPG, Accenture, Http://venturebeat. com/2013/06/10/walmart-scoops-up-inkiru-to-bolster-its-big-data-capabilities-online/[Accessed 15 October 2013].

- Kim, G.; Shin, B. and Kwon, O. (2012). "Investigating the Value of Sociomaterialism in Conceptualizing IT Capability of a Firm", Journal of Management Information Systems, 29, pp. 327-362.

- Kiron, D.; Prentice, P. K. \&and Ferguson, R. B. (2014). “The Analytics Mandate", MIT Sloan Management Review, 55, pp. 1-25.

- $\quad$ Kiron, David and Shockley, Rebecca. (2011). "Creating bBusiness Value With Analytics" (Survey). MIT Sloan Management Review, 53(1), 57.

- $\quad$ Lind, Douglas A.; Marchal, William G. and Wathen, Samuel A. (2012). Statistical Techniques in Business and Economics. McGraw-Hill, pp. 317-318.

- $\quad$ Liu, Y. (2014). “Big Data and Predictive Business Analytics”, The Journal of Business Forecasting, 33, pp. 40-42.

- Makrufa S. Hajirahimova; Baku, Azerbaijan and Albeniz S. Aliyeva. (2016). Big Data Strategies of the World Countries. Institute of Information Technology, Azebaijan National Academy.

- Mcafee, A. and Brynjolfsson, E. (2012). "Big Data: The Management Revolution", Harvard Business Review, 60-6, 68, 128.

- Omerzel, D. G. and Gulev, R. E. (2011). "Knowledge Resources and Competitive Advantage", Managing Global Transitions, 9, (4), p.335.

- Preimesberger, C. (2011). “Big Ideas about Big Data”, Eweek, (28:13), pp. 34-37.

- $\quad$ Ravichandran, T. and Liu, Y. (2011). “Environmental Factors, Managerial Processes, and Information Technology Investment Strategies," Decision Sciences, Vol. 42, No. 3, pp. 537-574.

- $\quad$ Suhong Li, Nathan, B. R., Nathan, T. S. R and Rao, S. S. (2004). "The Impact of Supply Chain Management Practices on Competitive Advantage and Organizational Performance, omega 2004, 34, pp.107-124.

- $\quad$ Tweney, D. (2013). Walmart Scoops Up Lnkiru to Bolster its 'Big Data'Capabilities, online [Online]. Available:

- UN Global Pulse. (2012). Big Data for Development: Challenges \& Opportunities- White Paper, Available at http://www.unglobalpulse.org/projects/bigdatafordevelopment, May 2012.

- Wade, M. R. and Nevo, S. (2011), "Firm-level Benefits of IT-enabled Resources: A Conceptual Extension and an Empirical Assessment", The Journal of Strategic Information Systems, 20, pp. 403-418

- Ward, D. G. J. D. (2014). "A Guide to the Strategic Use of Big Data", Information Management, 48, pp. 45-47.

- Wills, M. J. (2014). "Decisions Through Data Analytics in Healthcare", Journal of Healthcare Management, 59, pp. 254-62. 